\title{
"LA CUESTIÓN DEL RÍO LAUCA" DESDE LA PERSPECTIVA MULTIESCALAR: ¿UN JUEGO DE SUMA CERO DE LAS DIPLOMACIAS BOLIVIANA Y CHILENA?*
}

\author{
“THE LAUCA RIVER PROBLEM” FROM THE MULTI-SCALAR PERSPECTIVE: \\ A ZERO-SUM GAME OF BOLIVIAN AND CHILEAN INTERNATIONAL \\ RELATIONS?
}

\author{
Sergio González $z^{* *}$, César Ross ${ }^{* * *}$, Cristián Ovando ${ }^{* * * *}$
}

\begin{abstract}
Se estudia el contexto histórico de la "cuestión del río Lauca", identificando diferentes actores y escalas de análisis y sus consecuencias en el desarrollo del conflicto que concluyó con la ruptura de relaciones diplomáticas entre Bolivia y Chile. Se conjetura que las diplomacias de ambos países en su intento por establecer sus posiciones frente a los escenarios nacionales e internacionales, donde la mediterraneidad boliviana fue el problema de fondo, no lograron prever las consecuencias políticas que llevaron a un diferendo fronterizo de baja intensidad a escalar a un conflicto internacional de alta intensidad. Se analizan algunas posiciones heterodoxas de personajes bolivianos y chilenos para solucionar el litigio. También se hace referencia al impacto de este litigio en el desarrollo local y regional de la actual Región de Arica y Parinacota.
\end{abstract}

Palabras claves: relaciones diplomáticas, análisis multiescalar, regiones fronterizas.

The historical context of "the Lauca River problem" is studied, identifying different actors and analysis scales and its consequences in the development of the conflict that finished with the breakdown of diplomatic relations between Bolivia and Chile. It is speculated that international relations of both countries, in their attempt to establish their own positions facing the national and international scenes, where the Mediterranean Bolivian feel was the basic problem, could not foresee the political effects that led to a border dispute of low intensity to an international conflict of high intensity. Some heterodox positions of important Bolivian and Chilean figures are analyzed to solve the dispute. It is also mentioned the impact of this disagreement in the local and regional development of the current Arica-Parinacota region.

Key words: diplomacy relations, multi-scalar analysis, border regions.

\section{Introducción}

En este artículo revisaremos algunas de las principales aristas del litigio diplomático por las aguas del río Lauca entre Bolivia y Chile, destacando la perspectiva regional de este problema. Las aristas que abordaremos son las siguientes: 1 . la importancia de los proyectos de irrigación para los valles precordilleranos de las antiguas provincias de Arica y Tarapacá; 2. Los efectos no deseados del conflicto del Lauca, más allá de los avatares diplomáticos; 3. Las anomalías del juego de suma cero: las propuestas de solución fuera de agenda diplomática; 4. Dos perspectivas con sentido de realidad; 5. La crisis económica de Arica en el contexto del litigio de las diplomacias boliviana y chilena.
La importancia histórica del litigio entre Bolivia y Chile por las aguas del río Lauca es haber sido la razón de la primera ruptura de relaciones diplomáticas entre ambos Estados nacionales desde la firma del Tratado de Paz y Amistad de 1904. A pesar de las diferencias y desencuentros notorios entre ambos Estados nacionales, especialmente a partir de 1919 por la demanda boliviana en torno a un acceso soberano al océano Pacífico, en esos cincuenta y ocho años no se alcanzó una tensión que ameritara la ruptura de relaciones diplomáticas. Paradojalmente la acción chilena de desviar parte del flujo de agua del río Lauca generó un conflicto que podría calificarse de escala menor en comparación con el problema de la mediterraneidad boliviana, sin embargo, la forma como se desarrolló la controversia

\footnotetext{
* Resultado Proyecto Anillos SOC 1109, CONICYT: "Relaciones transfronterizas entre Bolivia y Chile: Paradiplomacia y prácticas sociales 1904-2004".

** Universidad Arturo Prat, Instituto de Estudios Internacionales. Iquique, Chile. Correo electrónico: pampino50@ gmail.com

*** Universidad de Santiago de Chile, Instituto de Estudios Avanzados. Santiago, Chile. Correo electrónico: cesar.ross@ usach.cl

****Universidad Arturo Prat, Instituto de Estudios Internacionales. Iquique, Chile. Correo electrónico: covando@unap.cl
} 
llevó a Bolivia a romper relaciones diplomáticas con Chile el 17 de abril de 1962. No debemos olvidar, como veremos en apartados posteriores, que desde 1952 Bolivia es un país diferente y quizá 1962 también refleje ese cambio. Por ejemplo, después de 1959 (Revolución Cubana) la lucha en contra de los imperialismos tiene nueva fuerza; junto con ello debemos destacar que el contexto internacional latinoamericano estaba marcado también por un creciente panamericanismo, la emergencia del movimiento de los "no alineados". A ello, agregar que tal vez lo menor (litigio del Lauca) siempre fue reflejo de lo mayor (reivndicación marítima) en este conflicto.

A partir de ese momento se realizaron gestiones por distintos organismos, en particular por la Organización de Estados Americanos, OEA (Tomasek, 1967), para reanudar las relaciones diplomáticas, empero ambos Estados nacionales iniciaron un complejo intercambio de argumentos hasta 1975, cuando los presidentes militares Banzer y Pinochet se reunieron en el poblado de Charaña, resolviendo simbólicamente en un abrazo la vuelta a la normalidad diplomática entre ambas naciones. Tácticamente el problema de las aguas del río Lauca quedó silenciado bajo la sombra de una posible solución al problema de la mediterraneidad boliviana. Con el "abrazo de Charaña" los rebuscados argumentos diplomáticos de uno y otro gobierno para explicar "la cuestión del Lauca" quedaron temporalmente en el olvido ${ }^{1}$. Entonces: ¿Qué fue -desde una perspectiva diplomática- el conflicto por las aguas del río Lauca? ¿Fue una estrategia boliviana para volver a discutir el problema de la mediterraneidad, como lo afirmaron diplomáticos y especialistas chilenos de la época? ¿Fue una estrategia chilena para desviar la discusión acerca de la mediterraneidad hacia otros conflictos de menor intensidad, pero que escaló a un umbral superior llegando a la ruptura de las relaciones diplomáticas entre ambos Estados nacionales? ¿Fue un problema no previsto derivado de las nuevas fronteras surgidas de los Tratados de Chile con Bolivia (1904) y con Perú (1929)? ¿Fue una centenaria necesidad de agua en regiones desérticas, tanto del sur peruano como del norte de Chile, donde la cordillera de los Andes ha sido el principal proveedor de este recurso, y que la diplomacia boliviana utilizó para construir una hipótesis de conflicto?

El conflicto por las aguas del río Lauca presenta un caso con diversas aristas que pueden analizarse de forma independiente y también como una compleja totalidad, donde el objetivo de las contrapartes no es llegar necesariamente a un acuerdo sino presentar el peso de sus argumentos, pero no solo frente al adversario sino a un tercero teórico, que puede ser: su propia sociedad como un árbitro de facto, un futuro tribunal internacional como el de La Haya, una organización interamericana como la OEA, los países vecinos como Brasil y Argentina, a las regiones y comunidades directamente afectadas, etc., también puede ser la Humanidad o la disciplina de las relaciones internacionales, particularmente las teorías que se aproximan a la existencia de un pluralismo diplomático que va más allá de la diplomacia oficial.

Una de las aristas más interesantes de "la cuestión del río Lauca" es que -por medio de él- las diplomacias en realidad están litigando respecto de otro conflicto que es la "mediterraneidad boliviana", obligándoles a un juego de suma cero respecto del Lauca.

Estimamos que esta afirmación es la clave de por qué el conflicto en torno al Lauca escala de lo menor a lo mayor: es un símbolo de lo mayor, y escaló inevitablemente; o era parte de una estrategia mayor, donde la táctica era, mediante el Lauca, provocar la negociación (Bolivia) o evitar la negociación (Chile). La cuestión es que el equilibrio en este juego de cálculo pendía de una relación muy frágil, donde la estabilidad y normalidad (diplomática) de las relaciones podía perderse muy fácilmente.

Si a juzgar por los antecedentes el juego siempre fue de "suma cero" y no de "suma variable", es la señal de que siempre se estuvo hablando de salida soberana al mar, cuestión que se resolvería con un sí o un no, y no del Lauca, en cuyo casi sí se podría haber negociado tradicionalmente en un arreglo de suma variable, o sea, con una distribución parcializada de los derechos de uso o posesión.

En suma, la diplomacia boliviana intentó transformar la demanda por las aguas internacionales del río Lauca en una discusión abierta acerca de la "mediterraneidad boliviana" y, la chilena, trató evitar que "la cuestión del río Lauca" salga de los límites del derecho internacional respecto del uso de las aguas de ríos internacionales y termine siendo parte de la demanda boliviana por el Pacífico.

Por tanto, frente a un juego de lógicas diplomáticas tradicionales, inspiradas en principios propios de las políticas exteriores respectivas, como es el caso de la integridad territorial, entre otros elementos del autodefinido interés nacional, surge la perspectiva 
más amplia en torno a las posibilidades que aporta una diplomacia "plural" (Cornago 2013). Lo que hace necesario tener en cuenta a la diplomacia como una cuestión por encima de las preocupaciones y conocimientos del arte de gobernar (aunque esto, no cabe duda, sigue siendo fundamental y valioso). Se requiere el fomento de los conocimientos a partir de una diversidad de fuentes que no estén orientadas a afirmar las certezas soberanas de los Estados y las agendas de prioridad de sus políticas (Constantinou, 2013:142,143)

No obstante, es posible hacer la siguiente precisión. La diplomacia es una herramienta de la política exterior y en tal sentido los diplomáticos son mandatados por un principal (mandante) que es el Presidente de la República que, por medio de su Ministro de RR.EE. ejecuta su política. Si centramos la atención en la diplomacia, implícitamente (teoría de agencia), estamos diciendo que los mandatados (diplomáticos) están haciendo una política que puede diferir, en grados variables, de la política del mandatario. Esta posibilidad estaría dada, en nuestro caso, por la posibilidad de movilizar creencias respecto del tema que tengan los actores alojados en distintas escalas, pudiendo ajustar sus preferencias a la agenda diplomática. Siguiendo este razonamiento, es totalmente posible argumentar que esta política central dejó de ver lo que ocurría en "los bordes" de esta historia y que a ese nivel, las mismas preguntas que los Ministerios de RR.EE respondían de un modo, se respondían de manera diferente.

Teniendo en cuenta esta premisa, emerge la pregunta de la región supuestamente beneficiada por el desvío de las aguas del río Lauca. En 1962 Arica formaba parte de la provincia de Tarapacá, aunque la zona directamente involucrada en la discusión por el desvío de las aguas del río Lauca eran los valles de Azapa y Lluta. ¿Cuál era la visión de la comunidad ariqueña frente a este litigio diplomático que, supuestamente, por un lado le beneficiaba y, por otro, podía significar la entrega de parte de su territorio a otro país, incluyendo comunidades altoandinas? ¿Qué tan necesario o artificial era el desvío las aguas del Lauca para los valles de Arica?

\section{Los proyectos de regadío con aguas altoandinas}

Las sociedades andinas fueron culturas hidráulicas, desarrollaron tecnologías que todavía asombran a los investigadores (Castro et al. 1991). A fin de la Colonia y comienzos de las repúblicas en las provincias de Tacna, Arica y Tarapacá (tanto durante el periodo peruano como el periodo chileno) se diseñaron importantes proyectos de regadío para aumentar el agua en los valles precordilleranos y también proyectos de regadío en la pampa del Tamarugal, como una necesidad fundamental para la vida en una zona desértica.

Hacia 1619, durante el gobierno del virrey Francisco de Borja y Aragón, las aguas del río Lauca fueron vistas por el Cabildo de Arica como una solución para superar la "situación de abandono que sufría la ciudad y su área circunvecina" (Hidalgo 1985:184), al regar el valle de Azapa. Es decir, no fue durante el gobierno del presidente Pedro Aguirre Cerda que este proyecto de regadío estuvo por primera vez en la mente de los ariqueños en la búsqueda de una solución a sus necesidades agrícolas. Las diplomacias boliviana y chilena plantean el problema del uso de las aguas del río Lauca (y de los demás ríos altiplánicos) como un fenómeno contemporáneo divorciado de una larga tradición de las comunidades que han habitado esa zona desde épocas antiguas.

Posiblemente el trifinio instalado en la meseta altiplánica de Ancomarca que establece el hito 80, para Perú y Chile, y 5, para Bolivia y Chile, sea el símbolo más notorio de la presencia de los Estados nacionales en una zona que fue un territorio andinoaymara sin más límites que la naturaleza misma y la cosmovisión de sus habitantes. El cronista Lozano Machuca (1581) hace referencia a una obra del incario para desviar las aguas del río Mauri. Una fracción de sus aguas fue desviada hacia la provincia de Tacna con fines agrícolas, generándose un conflicto diplomático con Bolivia cuando Chile ocupaba esa provincia. Este conflicto diplomático lo heredó Perú, sin embargo, fue resuelto después del Tratado de 1929. Siguiendo a Jorge Hidalgo, el Gobernador de Arica, Tomás Bocardo Messia (1735-1739), propuso el desvío de las aguas de los ríos Uchusuma y Ancomarca para el valle de Tacna (1985:184). Actualmente podemos constatar la existencia de un canal construido por Chile cuyas aguas van en dirección de los valles tacneños, pues el Tratado de 1929 entre ambos países consideró el uso de las aguas de los ríos Mauri y Uchusuma, que pasan por territorio chileno, para beneficio peruano (Niemeyer 1980). 
Sin duda, el desvío de las aguas altiplánicas -en esa época como en la actualidad-podría significar un impacto ecológico y económico para las poblaciones andinas (Bernhardson 1985) y, también, un beneficio para agricultores o compañías mineras transnacionales (Van Kessel 1985). Aquí solamente queremos sostener que los proyectos de desvío de aguas altiplánicas no son un fenómeno exclusivo del siglo veinte asociados a la presencia chilena en estas regiones, sino que tienen antecedentes remotos, incluso algunos de esos proyectos como los de Mendizábal en la quebrada de Tarapacá y O'Brien respecto de las aguas de Lirima (Larraín 1974, Castro 2004) tenían una escala superior a los proyectos actuales. Lo anterior señala claramente la necesidad regional de una utilización más racional del recurso hídrico en regiones desérticas que, incluso, debería considerar proyectos transfronterizos de desarrollo, o el reconocimiento de regiones asociativas de frontera (Boisier 1987). Sin embargo, veremos más adelante cómo desde la diplomacia o cierta intelectualidad boliviana se sospecha de este tipo de iniciativas regionales de integración.

Los Estados nacionales de Bolivia y Chile nombraron Comisiones de técnicos y especialistas para que analizaran el impacto ecológico, social y económico que podría significar el desvío de una fracción (para Chile insignificante y para Bolivia fuera de norma) de las aguas del río Lauca. Lamentablemente, el litigio tomó otro rumbo que tuvo por resultado la ruptura de relaciones diplomáticas. ¿Cuál diplomacia ganó la partida con ese resultado? Para Chile supuestamente significó el beneficio económico de desviar las aguas y resolver el problema del desarrollo de Arica. Para Bolivia el beneficio comunicacional de seguir denunciando a Chile en los foros internacionales respecto del problema de la mediterraneidad, ahora con un argumento adicional.

Los ríos altiplánicos no son navegables, tienen escaso caudal de agua, el gasto del río Lauca al desembocar en el lago Coipasa es de 8 a $16 \mathrm{~m}^{3} / \mathrm{seg}$, y según la posición chilena, la mayor parte de esta agua termina evaporándose en los salares andinos. Chile "solo utiliza un cuarto del área colectora ubicada en territorio chileno; el resto, o sea $3 / 4$, drena hacia Bolivia" (MRREE 1963:5). Si estos argumentos son ciertos, el costo para Bolivia sería bajo en consideración de su campaña internacional de afianzar su argumento de Chile como potencia agresora que, esta vez, unilateralmente se apropiaba de las aguas del río Lauca. Efectivamente, Chile sospechó que
Bolivia llevaría la demanda boliviana a la Conferencia Interamericana en Quito, pero no respecto del río Lauca, sino acerca de la mediterraneidad:

Sorpresivamente, fue informado nuestro
Gobierno de que Bolivia tendría el propósito
de pedir que la Conferencia Interamericana
que debía reunirse en el mes de mayo de
ese año (1961), en Quito, se ocupara del
problema de su mediterraneidad. Con este
motivo, se había convocado, en La Paz, a
una reunión de notables de la Presidencia
de la República.
Pero no hubo entonces necesidad de cumplir
tales instrucciones, porque la Conferencia
de Quito fue postergada en forma indefinida.
Desgraciadamente, poco tiempo después, se
inició en la opinión pública una campaña
pro reintegración marítima. Se anunció
que la nueva Constitución Política del
país vecino, que se encontraba en estudio
en el Parlamento, la incorporaría, como
precepto constitucional.

En el juego diplomático (supuestamente concerniente a las aguas del río Lauca), ambos Estados nacionales lograron sus objetivos, pero perdieron sus vínculos bilaterales que el orden internacional aconseja para las sociedades modernas, estos es, relaciones diplomáticas normales.

En suma, para el "universo andino", en tanto escala involucrada en el conflicto del Lauca, no se trata de un río más y mucho menos para las comunidades implicadas directamente. Ello complica la visión del centro, que rodeada del recurso agua, quizá vio que se trataba de algo menos importante. Por tanto, en su propia escala, el conflicto por el Lauca fue de vida o muerte para las comunidades locales y sus economías agrícolas.

Banalizado así el conflicto, las diplomacias y las políticas centrales quizá no advirtieron que esto podría escalar como lo hizo (por la capacidad local de influir en la agenda central), sin perjuicio de que además el Lauca fuera una excusa para ocultar los eventuales y verdaderos propósitos de La Paz y Santiago.

\section{Los efectos no deseados del conflicto del Lauca, más allá de la diplomacia tradicional}

Además de la pérdida de las relaciones diplomáticas entre ambos Estados nacionales que, sin 
lugar a dudas, tuvo un impacto multiescalar en ambas sociedades.

\section{Las escalas regional y local-transfronteriza}

En el conflicto del Lauca, las poblaciones de las escalas regional y local transfronteriza fueron las principalmente afectadas. Un ejemplo es la noticia que se recibió en Iquique el 1 de enero de 1962, cuando el ministro boliviano de Obras Públicas, Mario Sanginés, suspendió su entrevista con su par chileno Ernesto Pinto Lagarrigue, donde se trataría el tema del camino Iquique-Oruro, debido al problema del Lauca. Los iquiqueños lo atribuyeron a su "mala estrella", debido al largo periodo de lucha por ese objetivo.

El diario El Tarapacá de Iquique del 1 de enero de 1962, recoge así esa noticia:

Antes de su visita oficial al país el Secretario de Estado del Altiplano estuvo algunos días en Arica, lo que preocupó a los dirigentes iquiqueños, tras de los cuales-por gentileza del Club Aéreo-se movilizaron al vecino puerto y se entrevistaron con el Ministro para manifestarle la inquietud reinante en la ciudad ante su intempestiva visita. Sin embargo, mantuvo su posición en el sentido de ser partidario de la ruta Iquique-Oruro, tal como lo había manifestado en La Paz. En esa misma ocasión los personeros locales invitaron al Ministro Sanginés para que en el terreno mismo se impusiera de las garantías que el puerto le ofrecía a las mercaderías de importación y exportación del Altiplano. Aceptó, expresando que lo haría al finalizar su entrevista con Ernesto Pinto.

Cuando faltaban pocos días para el arribo del Secretario de Estado, se suscitó un bochornoso incidente en La Paz en contra de Chile, a raíz de la desviación del río Lauca, cuyos pormenores conoce ampliamente la opinión pública.

De inmediato se suspendió la visita del Ministro y quedaron suspendidas todas las gestiones en torno a la construcción del Camino Internacional. De esta forma, la mala estrella de los iquiqueños se evidenció de una vez más, cuando existían muchas probabilidades de obtener su cometido.
Por cierto, en Oruro la opinión fue similar, pero más optimista, pues señalan que "No debemos desanimarnos y debemos continuar en la tarea hasta verla realizada", agregando: "Por suerte los fuegos de la vehemencia chauvinista se han extinguido".

El Tarapacá del 14 de febrero de 1962, registra de ese modo la nota orureña:

Una comunicación que refleja el interés que tienen los orureños por reactivar las gestiones para obtener la construcción definitiva del Camino Internacional Iquique - Oruro, recibió el señor Alfonso Valjalo, Presidente del Comité Pro Construcción de la vía, de parte del Presidente de la Unidad Para el Progreso de la citada ciudad boliviana, señor Josermo Murillo Vacareza.

El señor Valjalo remitió copias de esta comunicación, que se indica como móviles políticos el asunto del río Lauca, al Alcalde de la Comuna y al Presidente del Centro Para el Progreso.

Por considerarlo de interés para las pretensiones de resurgimiento de la zona, y en procura de reiniciar la hasta hace poco bien llevada campaña, damos a conocer algunos acápites de la carta del dirigente orureño. Dice:

"Si bien los incidentes artificialmente provocados con motivo de la desviación del río Lauca, parecieron haber destruido todo cuanto veníamos haciendo en favor del camino, estimo que es simplemente un incidente que pudo haber retrasado esta labor, pero que quizás hasta sirva para estimularlo".

"Por ello nos mantenemos nosotros en la más decidida posición para promoverla, ya que es vital para la zona de integración económica y social que forma el Altiplano de Oruro con el Norte de Chile y, particularmente, con la provincia de Tarapacá; por suerte los fuegos de vehemencia chauvinista se han extinguido y nuevamente podemos actuar dentro de una atmósfera serena". La comunicación está fechada el 23 de enero en la ciudad de Oruro.

Esta lucha por la integración física entre Oruro y Tarapacá fue impulsada en 1864 por el primer proyecto ferroviario del minero boliviano, 
José Avalino Aramayo, junto al ingeniero alemán, Hugo Reck (Gómez Zubieta 1998), para después ser continuada por diversos proyectos ferroviarios (Castro 2003) hasta concluir en la ruta para camiones de carga pesada hacia 1928 (Harms Espejo 1930). En 1958 las poblaciones de Oruro y Tarapacá fueron testigos de las primeras caravanas orureñas y tarapaqueñas que cruzaron los Andes para demostrar simbólicamente el deseo y la necesidad de la construcción del mentado camino (González 2011). Nada más ajenas al conflicto por el Lauca son estas poblaciones de Oruro y Tarapacá y, con mayor razón, su demanda de integración física en pos de un desarrollo regional complementario.

Sin embargo, el conflicto diplomático por una fracción de los 2.500 litros por segundo que se calculaba arrastraba este río, escaló a un nivel inesperado por ambas diplomacias. El historiador y diplomático boliviano, Jorge Escobari Cusicanqui, plantea, sin embargo, que la iniciativa orureña por lograr una ruta hacia Tarapacá responde a una estrategia chilena, a saber: "Bolivia confronta ahora un dilema: o seguir estimulando el desarrollo de Arica con las actividades económicas bolivianas, o complacer a Chile creando -además de Antofagasta y Arica- un nuevo 'polo de influencia' chilena desde Iquique con proyecciones sobre Oruro, Cochabamba y Santa Cruz de la Sierra" (1978:49). Este especialista utiliza un lenguaje propio del enfoque realista de la disciplina de relaciones internacionales, ancladas en los vínculos exclusivos entre Estados nacionales y marcados por las estratagemas de la diplomacia estatal, que apuestan por la mera defensa de los intereses autodefinidos como nacionales (Constantinou, 2013). Con ellas explica el fenómeno fronterizo que, en cierta forma, está ubicado en las escalas regional y local, y que, conjeturamos, se aproxima a vínculos que experimentan con expresiones que permitan ensayar la reconciliación de formas rivales de existencia (Constantinou, 2013). Escobari Cusicanqui remata: "Todo esto nos mueve a reflexiones inquietantes: Por una parte, existe el legítimo derecho de la población orureña de contar con una vía de acceso rápida y conveniente al Pacífico, pero, por otra, se cierne el designio chileno de perfeccionar cada vez más el enclaustramiento boliviano para obtener el desarrollo del norte de Chile con las exigencias económicas de Bolivia a través del litoral" (1978:150). Resulta interesante que, por un lado, los proyectos de integración física que tendrían por finalidad un mayor acceso de Bolivia a los puertos del Pacífico, sean vistos como una estrategia geopolítica chilena para proyectarse por el continente por medio de Bolivia y, por otro lado, se señale que "gran parte de las graves dificultades que confronta Bolivia para su progreso efectivo, provienen de la carencia de ese contacto propio con el Océano Pacífico" (Escobari 1973:145).

\section{La escala nacional bilateral}

A escala nacional también se generaron efectos no deseados por ambos gobiernos, uno de ellos fueron las violentas manifestaciones antichilenas en Bolivia:

Un temporal desató recientemente en el
Altiplano la desviación unilateral de las
aguas del río Lauca, que mansamente bajan
por la cordillera andina hacia el valle de
Azapa, como lo muestra el grabado. El
Lauca nace en territorio chileno y muere en
tierras bolivianas. Por causa de este entre-
dicho, cuya solución espera la ciudadanía,
en La Paz, Oruro, Potosí y otros centros
mineros, se realizaron manifestaciones
antichilenas, que involucraron incluso la
quemazón de una bandera nacional, y el
apedreamiento de dependencias diplo-
máticas de nuestro país. El Gobierno de
La Moneda, en un extenso memorándum
entregado al Gobierno de La Paz, hizo valer
la legalidad de sus procedimientos y la
corrección en que se inspiró la desviación
del río. Una respuesta sobre el particular
es esperada con impaciencia. ${ }^{3}$

Lo complejo del problema anterior fue la presencia -como instigador- del vicepresidente de Bolivia, el dirigente sindicalista, Luis Lechín. Esto significó un duro cuestionamiento en la propia Bolivia al gobierno del presidente Paz Estenssoro. El Diario de La Paz del 24 de diciembre de 1961, en su página 14, trae una larga declaración del Partido Revolucionario, donde señala en una de sus partes:
III. Defensa del interés nacional o maniobra de política interna?
Descontento contra del Gobierno. No solo la opinión pública boliviana sino la del continente, están al cabo de existen 
en nuestro país un descontento agudo a inquietante contra del Gobierno, una efervescencia popular que busca un cauce para expresarse y tomar cuerpo. Ese es el resultado más perceptible de año y medio de régimen Paz-Lechín.

En tal clima político, la desconsiderada e imprudente frase última de la nota chilena, produjo una reacción fácil e inmediata. Los estudiantes hicieron una manifestación la primera semana de diciembre y luego surgieron otras expresiones públicas de protesta. La característica de todas ellas fue que estaban dirigidas contra el gobierno. Era evidente que el Presidente Paz Estenssoro estaba ante el riesgo de que el asunto del río Lauca se volviera como una avalancha contra su régimen que había abandonado este problema, como tantos otros, mientras se ocupaba de inventar subversiones, perseguir ciudadanos y perseguir a los áulicos.

Maniobra del Presidente Paz Estenssoro, fiel a su naturaleza el Presidente Paz Estenssoro hizo frente a esa situación con una maniobra más bien que con una medida de hombre de Estado. Decidió que el oficialismo tomara en sus manos la bandera de las protestas contra Chile, encauzándolas exclusivamente contra ese país, para hacer olvidar tanto la responsabilidad de su Gobierno como el descontento popular. La herida siempre abierta del desmembramiento territorial y el enclaustramiento, facilitó su acción. Hizo algo más. Dentro de esa maniobra general, puso en práctica otra maniobra más pequeña consistente en utilizar a la C.O.D. que es uno de sus instrumentos y al vicepresidente Lechín para empujar, encabezar y dirigir las manifestaciones populares contra Chile. De ese modo, esperó disimular su responsabilidad personal en todo este proceso.

En Chile pedimos disculpas, mientras todas esas cosas sucedían dentro del país. Veamos qué hizo el Gobierno para defender los derechos de la nación sobre el río Lauca. El 26 de noviembre (4 días después de entregado el Memorándum comentado) el embajador Monroy, entrevistado al salir de una conferencia con el Ministro de
Relaciones Exteriores de Chile Sr. Carlos Martínez Sotomayor, para tratar la postergación de la visita del Ministro Sanginés Uriarte declaró lo siguiente:

"Esta conversación ha tenido por objeto coordinar la próxima visita que hará a Chile el Ministro de Obras Públicas de mi país, ya que ha sido postergada hasta nueva fecha que será fijada por los dos gobiernos de común acuerdo. Mientras se resuelva algunos detalles de carácter administrativos" (a eso quedó reducido el asunto del Lauca).

El gobierno de Chile no quedó al margen de la crítica en algunas publicaciones de Santiago, como fue el caso de la revista Vistazo en su número 482, donde se señala lo siguiente:

La Historia de las discusiones chilenobolivianas sobre la utilización de las aguas del río Lauca es antigua, y los únicos y verdaderos culpables de que aún el problema no se haya superado, son todos los gobiernos que, tanto en Chile como en Bolivia se han venido sucediendo desde 1934.

Lo interesante de esta publicación es que sube el nivel de la escala del análisis, para situar "la cuestión del Lauca" a nivel continental, como veremos más adelante. La problemática de las aguas del Lauca, además, como un efecto secundario positivo, puso atención -desde el punto de vista del pluralismo diplomático, orientado por intereses humanistas más allá de formalismos diplomáticos (Cornago 2013; Constantinou y Der Derian, 2010 y Constantinou, 2013) - en los pastores andinos (Bernhardson 1985), que hasta entonces estaban invisibilizados. Un río altiplánico de escaso caudal en el vértice de la antigua provincia de Arica logró interesar a los intelectuales y científicos en el problema del desarrollo del altiplano. Siguiendo a Luis Galdames y Rodrigo Ruz, más allá de las obras de infraestructura, conectividad y equipamiento que la J.A.A. gestionó para la provincia, comenzó a discutirse ideológicamente acerca del concepto de "lo andino", donde académicos de las ciencias sociales que llegarán a tener gran reconocimiento en el tema como "Tristán Platt y las influencias cercanas de Gabriel Martínez desde Isluga. La etnohistoria, en tanto, quedó en manos del único cultor de la época: 
Jorge Hidalgo, ligado fuertemente a John Murra" (Galdames y Ruz 2010:258), este último tendrá un papel intelectual relevante: "Estas ideas fueron recogidas tempranamente por el Departamento de Antropología de la Universidad del Norte y la J.A.A., otorgando un espacio de discusión para las temáticas andinas, en donde la experiencia de John V. Murra venía a fortalecer el interés de ambas instituciones por comprender las dinámicas culturales, sociales y económicas de la población andina ariqueña" (Galdames 2010:259). El conocimiento de estos intelectuales, siguiendo a Hans Gundermann y Héctor González, respeccto del mundo andino, provenía "de su participación en algún proyecto específico (como el Plan Andino impulsado por la Municipalidad de Iquique a fines de 1960), y del conocimiento de iniciativas desarrollados en la zona por la Corporación de Fomento (CORFO), la Corporación de la Reforma Agraria (CORA) o la Junta de Adelanto de Arica. El grupo se disuelve con el golpe militar" (2009:118). Lo más relevante de estas visiones de la época, a pesar del dominio intelectual del estructuralismo, se enfocaron en los actores más marginados, como los agricultores y pastores andinos. Por tanto, otros autores consideran que en la discusión de la integración de la subregión andina o a escala región-región ( $v . g r$. La Paz-Arica; Oruro-Tarapacá) la interculturalidad es condición necesaria en los proyectos de desarrollo complementario, sean económicos, políticos o diplomáticos (González 2006).

\section{La escala continental e internacional}

Quizás más sorprendente que el interés de los intelectuales pertinente a "la cuestión andina" a partir de la "cuestión del Lauca" es la vinculación que algunos analistas, tanto en Bolivia como en Chile, hacen de este conflicto por las aguas de un río altiplánico con el "imperialismo norteamericano".

La revista chilena Vistazo lo define como el oscuro juego.

Hasta aquí todo iba por el habitual canal diplomático. Y por él debería haber ido siempre el entredicho, de no haber mediado el caso Cuba y la acumulación de problemas internos, tanto el gobierno boliviano como en el chileno. Estos dos factores más el siniestro juego de perturbaciones internacionales que Estados Unidos y su
Central de Inteligencia están desatando en todos los países del Continente como instrumento de presión sobre sus gobiernos, se coludieron para darle al caso un nuevo filo. A todo esto iba caminando por el continente una nueva agresión a Cuba. El día 4 de diciembre el gobierno chileno al fin contestó la nota, rechazando el planteamiento boliviano, y el 6 se produjeron en La Paz, y jamás alcanzaron la virulencia que las agencias noticiosas le dieron. Y bien, el problema cubano reventó súbitamente en Santiago de Chile, por esos mismos días. Se quebró la línea de "no intervención" de la Moneda, y el día 7, tratando de explicarse en una turbulenta sesión del Senado, el canciller chileno, Martínez Sotomayor, en una actitud insólita y jamás registrada en nuestra historia, recoge la provocación antichilena de los revanchistas bolivianos y dándole más impulso aún se queja que en Santiago no haya habido aún manifestaciones antibolivianas. Aquí el juego se hizo claro: se trataba de ocultar con el caso del río Lauca el vergonzoso traspié chileno ante la agresión a Cuba, y en Bolivia el asunto servía para echar humo sobre otras cosas.

Los analistas chilenos asociaron el traspié del gobierno chileno en torno a la condena a Cuba (1962 estuvo marcado por la Crisis de los Misiles, el embargo económico a la isla y salida de Cuba de la OEA) al problema del Lauca, considerando una cortina de humo la reacción del canciller Sotomayor ante el incidente (en la Paz) de la "quema de banderas chilenas". Para muchos Chile junto a otros países de la región violaron el principio de no intervención y de autodeterminación de los pueblos (Doctrina Estrada: reconoce a los Estados con independencia de sus formas de gobierno) al sancionar a Cuba debido a la injerencia de "imperialismo norteamericano". Aquí, la cuestión del Lauca se complica aún más al vincularse con la escala continental. No olvidemos que el panamericanismo liderado por potencias regionales -manifestado muchas veces mediante el establecimiento de arbitrajes, sanciones, etc.- ha sido considerado como un intento de quebrar la independencia de los Estados nacionales de América. Por ello, el principio de no intervención y el respeto de la soberanía fueron 
pilares de la agenda hemisférica del continente durante el siglo XX.

En estos mismos términos, los analistas bolivianos a su vez vinculan la cuestión del Lauca en la OEA.

Unidad, La Paz mayo de 1962, página 3

Provocación imperialista sobre el problema del Lauca.

Los hilos de la guerra sucia están siendo manejados por los imperialistas norteamericanos, interesados en fomentar el armamentismo y el fortalecimiento de los ejércitos nativos, a fin de aplastar en un baño de sangre la lucha de liberación de nuestro pueblo. De ahí que nos es nada casual el pedido hecho por lo jovencitos futres de la C.U.B. , en sentido que se arme al ejército y se desbanden las milicias sindicales, naturalmente en este pedido no incluyen los milicianos pagados por el Ministerio de Gobierno para reprimir al pueblo.

Esta misma provocación urdida por la reacción chilena con fines de diversión y levantada por el gobierno emerretista para distraer a nuestro pueblo, es utilizada por el imperialismo para reforzar las posiciones de sus huestes fascistas, de los clericales F.S.B., los reaccionarios del PARA, y demás auténticos.

El Pueblo, La Paz, 26 de mayo de 1962 ¿Por qué la OEA escabulló el bulto? Mientras que las cancillerías de Bolivia y Chile consideran "razonable" y "justiciero" el voto sobre el caso del Lauca, este semanario considera necesario e indispensable anotar un antecedente que se desprende de la decisión "oeista" que no se ha denunciado en nuestro país.

Bolivia acusó de agresión al Gobierno de Chile. El voto de la OEA elude esa acusación, decimos esto porque el informe de Washington de ayer (léase La Nación página primera) señala lo que sigue textualmente: "Bolivia acusando a Chile de cometer un acto de agresión por desviar una fracción del río Lauca, había pedido al Consejo una junta de consulta de acuerdo a los procedimientos contenidos en el Tratado Interamericano de Ayuda Recíproca. Ese
Tratado formulado en 1942 fue creado principalmente para proteger el Hemisferio contra actos de agresión desde fuera del Continente. Por esta razón, el Consejo ha estado renuente a aplicarlo en este caso (en el caso Lauca). Muchos delegados han expresado su opinión de que la aplicación en una disputa como esa (la del Lauca) debilitaría el Tratado". Se sabía que los 14 embajadores en la OEA, donde la influencia norteamericana es poco menos que decisiva, consideraron que la aplicación del Tratado de Río de Janeiro quedaría debilitada si se ejercitaba en el asunto Lauca. ¿Por qué ? Porque se iba a sentar un antecedente que, en el fondo, debilitaría a los EEUU. Si la OEA aprobaba, repetimos, la reunión de consulta de los cancilleres para discutir el caso de agresión, EEUU corría un riesgo: que mañana, ante sus constantes agresiones económicas y políticas y comerciales al continente Americano, un país demande la aplicación del Tratado de Río de Janeiro que, ahora, se muestra tal como es: un simple instrumento que solo debe hacerle el juego a los EEUU, para denunciar a título de agresión extra continental, por ejemplo, las relaciones con la Unión Soviética.

Con ello, la demanda boliviana por la cuestión del Lauca, invocando el TIAR, alcanza ribetes insospechados: junto con condenar la intromisión norteamericana en el ideario panamericanista, pone en jaque la feble estructura de seguridad colectiva recientemente creada en el continente, ya que invocándola para este caso EE.UU. también podría padecer eventualmente una decisión del TIAR.

\section{Dos perspectivas con sentido de realidad. Los casos del jurista boliviano Alberto Salinas Baldivieso y del científico chileno Hans Niemeyer}

Lejos de las visiones que pretendieron ubicar el caso del Lauca dentro de la guerra fría entre Estados Unidos y la Unión Soviética, es posible encontrar en esos momentos de mayor tensión, opiniones ilustradas con sentido de realidad.

El jurista boliviano, doctor Alberto Salinas Baldivieso, enfrentado a la siguiente pregunta, 
tuvo una respuesta que sorprende por su precisión y objetividad:

¿Ha caducado el derecho de Bolivia para contestar la demanda chilena sobre el uso y aprovechamiento de las aguas del río Lauca, de acuerdo con la declaración de Montevideo, en vista de no haberse hecho uso del mismo en los plazos de tres y seis meses estipulados?

La disposición VIII de la declaración de Montevideo, efectivamente señala los términos indicados para responder la denuncia y hacer observaciones. Tres meses para contestar y en caso que se organice una Comisión Mixta seis meses de término para presentar el informe correspondiente. Estos términos no se consideran fatales ni suficientes para concluir un diferendo. En materia internacional el procedimiento no puede cancelar un derecho, ni afectar la soberanía de un Estado. Además, el Acuerdo de Montevideo, es solamente una declaración que no hace sino ratificar una norma de derecho internacional, con respecto de los ríos internacionales y señala un procedimiento, al que pueden acogerse los Estados americanos a fin de facilitar un diferendo que podría surgir. La misma declaración dice: "Si dentro de ese plazo no se hubiere llegado a un acuerdo, expondrán los miembros sus opiniones respectivas, informando de ello a sus gobiernos".

La disposición novena y la décima, indican el camino para el caso de no llegarse a un acuerdo, primero la vía diplomática, segundo la Comisión de conciliación y, por último, el arbitraje.

¿Cómo cree que se deben encaminar las negociaciones bolivianas en el estado actual de las cosas, cuando ya se da una situación de hecho?

El camino está trazado, Bolivia ha recurrido ya a la OEA, si la conciliación no se produce, no resta sino el arbitraje. La conciliación en este caso, una vez que la obra está hecha sería la justa compensación, ya que la destrucción de la obra implicaría, un trabajo inútil de veintitantos años, un gasto gigantesco y una defraudación a la esperanza de miles de campesinos del valle de Azapa. Chile no aceptaría una solución de esta clase.

¿La actitud chilena constituye una agresión a Bolivia?

Agredir es provocar. Chile al desviar casi un $50 \%$ del río Lauca, de la hoya hidrográfica del Atlántico al Pacífico, sin consentimiento del "Condomine" de dicho río, que es Bolivia y con perjuicio de éste, ha incurrido en un delito internacional, porque lo ha hecho a ha hecho a sabiendas, con autorización de su gobierno, y con cierta malicia, sorprendiendo la buena fe del gobierno boliviano.

No le valen a Chile su argumento de que el Lauca nace en territorio chileno, las nacientes de un río internacional no determinan su propiedad. Es cierto que Bolivia, tan pronto como empezó el trabajo de canalización de dicho río, debería haber mandado al gobierno chileno para que suspenda la obra, hasta que se determine -en su caso-el mejor derecho. Sino se hizo esto, no se dio tampoco un consentimiento, ni tácito ni expreso, ya que siempre se protestó por esta obra, en forma oficial, ya que el pueblo no conoció de este asunto. Los defectos procedimentales, en este caso de soberanía estatal, no resuelven un conflicto internacional y no tienen valor como prueba decisiva contra un derecho de otro Estado. ${ }^{4}$

Por su parte, el arqueólogo chileno, Hans Niemeyer, quien además vivía en Arica como académico de la Universidad de Tarapacá, por tanto, conocía perfectamente la zona altoandina por donde cruza el río Lauca, enfrentado a explicar este litigio, lo resumió de la siguiente manera:

A partir de 1945, cuando se puso de moda el viejo proyecto, se organizaron comisiones conjuntas chileno-bolivianas que analizaron técnicamente el problema y se llegaron a importantes y definitivos acuerdos respecto a la desviación del río Lauca en su nacimiento a la salida de la Ciénaga de Parinacota, después que los pastores hacían uso de sus aguas y de las vertientes que afloran en su periferia y 
alimentan los tradicionales bofedales de pastoreo.

Un porcentaje relativamente pequeño del Lauca que atravesaba la frontera hacia Bolivia iría a regar el fértil valle de Azapa, evitando pérdidas del recurso originado en Chile por evaporación en el salar de Coipasa, base del equilibrio del sistema en el altiplano boliviano. Es cierto que por razones de cambios políticos no se perfeccionó el acuerdo en un tratado internacional, como ha ocurrido en otras ocasiones similares. Cabe, sin embargo, recordar los acuerdos con el Perú sobre aprovechamiento de este país sobre los recursos de los ríos Uchusuma y Mani que alcanzaron la categoría de tratado internacional, firmado el 3 de junio de 1929. Quiero dejar en claro que no me estoy pronunciando sobre la situación ética de usar las aguas de cordillera para la bebida y alimentación de las poblaciones costeras del Norte de Chile, privando parte de ellas a los pastores de la puna, sino establecer que el problema del aprovechamiento parte del Lauca tuvo un largo proceso histórico de acuerdos y conversaciones técnicas que precedió a las obras. ${ }^{5}$

La necesidad de hacer referencia a los pastores de la puna en este conflicto diplomático no podía evitarse desde la óptica regional, por un lado, y desde la antropología, por otro. Mirada que, en los años "del Lauca", todavía no se incluía en los estudios internacionales y menos en el campo de la diplomacia. Iver Neumann y su perspectiva antropológica de la diplomacia ha marcado una orientación en este sentido, especialmente su estudio referido al trabajo cotidiano de los diplomáticos (Sanz 2015: 700).

\section{Las anomalías del juego de suma cero: las propuestas de solución fuera de agenda diplomática. Los casos de Benjamín Subercaseux y Ricardo Anaya}

Tampoco las diplomacias pueden prever el comportamiento de los intelectuales, quienes, bajo el amparo de la libertad de opinión y de la libertad de pensamiento, cuando se trata de académicos, suelen levantar ideas que rompen la estructura del discurso oficial en litigios internacionales, como el caso del río Lauca. Ideas que buscan salidas heterodoxas que, a veces, son rechazadas de plano o deben esperar décadas para ser consideradas como factibles. Principalmente porque cuestionan dogmas propios del pensamiento moderno de las relaciones internacionales, como es el caso de la soberanía y la anarquía internacional, construidos desde una perspectiva logocéntrica (Ashley, 2009).

Se puede observar con claridad que, a pesar de la presencia institucional de la OEA en este conflicto, la ausencia de personajes y sus discursos relativos a la integración sudamericana para superar un conflicto de baja intensidad como lo fue el caso de las aguas del río Lauca y, sin embargo, toda América fue testigo del escalamiento de este litigio desde las comisiones técnicas bolivianas y chilenas hasta la ruptura de relaciones diplomáticas y la aparición de manifestaciones violentas antichilenas en diversas ciudades bolivianas.

Uno de los más prestigiados escritores chilenos, Benjamín Subercaseaux ${ }^{6}$, a pocos meses de la ruptura de relaciones diplomáticas entre Bolivia y Chile por el desvío de las aguas del río Lauca, en el marco de las escuelas de invierno de la universidad de Chile, en la ciudad de Antofagasta, planteó que "Arica, Lluta y Azapa deben ser la Tierra de Nadie $y$ de Todos, es decir un fideicomiso administrado por Chile, Perú y Bolivia”. Señalando además que: "Esa región debe ser un puerto totalmente libre, base para un Mercado Común y garantizada su estabilidad por las Naciones Unidas. Podría ser una zona de esparcimiento: para Bolivia satisfaría sus continuas pretensiones de salida al mar; el Perú no tendría problemas limítrofes y sería, además de un invernadero para nosotros por su buen clima, un excelente centro comercial". ${ }^{7}$

Subercaseaux no confía en el desarrollo industrial, agrícola o pesquero de Arica, pero sí en el agrícola si es que se cuenta con las aguas andinas, tangencial relación con las aguas del río Lauca, siendo lo central de su propuesta el concepto de "fideicomiso" tripartito de esa zona comprendida por Arica, Lluta y Azapa. Esta propuesta no podía ser considerada por las agendas diplomáticas de Bolivia, que pretendía una solución con soberanía plena de esa zona, y de Chile, que esperaba entonces discutir respecto de su derecho de las aguas del río Lauca y no el problema marítimo boliviano. Por tanto, la respuesta a este intelectual chileno provino de la subjetividad que portan los actores de las regiones del norte de Chile, en tanto imaginan 
un territorio -y sus posibilidades de desarrollo- no siempre coincidente con los determinados por las respectivas fronteras nacionales. En primer lugar, encontramos su propuesta en un editorial del diario El Mercurio de Antofagasta, donde se publicó la opinión de Subercaseaux y, en segundo lugar, desde Arica en el diario La Defensa de ese puerto.

En muy interesante la perspectiva que se expresa en La Defensa de Arica, porque se aleja de la visión oficial de la diplomacia oficial chilena y también de las respuestas nacionalistas que no se hicieron esperar, respondiendo a partir de la subjetividad regional, a saber:

Analicemos un poco todo lo que expresa. Creemos que a nuestro escritor se le ha pasado un poco la mano y que su proposición va a levantar olas de indignación y de oposición. No hagamos los patrioteros. Seamos realistas. Por encima de todo seamos nortinos y velemos por los intereses del Norte y por su porvenir.

Es inadmisible pensar siquiera que en Arica tenga injerencia otro país que no sea Chile. ¿Qué derecho podría exhibir cualquier país limitrofe para administrar nuestro puerto de Arica, o para tener incumbencia de cualquiera índole?

Es cierto, que cuando Arica dejó de ser puerto completamente libre empezó a vivir su martirologio y que todavía busca su camino. Pero tiene un destino señalado dentro del devenir histórico y económico de América Latina.

El momento es difícil porque hay gentes que necesitan trabajo, ya que mucha de su actividad estaba basada en el comercio de suntuarios y como eso se cortó demasiado bruscamente hay que buscar nuevos medios de vida.

$Y$ en eso se está, Decir que Arica no tiene capacidad industrial sería negar todos los factores que hicieron de esta ciudad un puerto libre. Decir que no es una zona con expectativas agrícolas es desconocer lo que dan y lo que debe producir los valles de Azapa y de Lluta, cada días más fecundos. Expresar que la pesquería no tiene porvenir es ignorar que la verdadera riqueza de Chile reside en la explotación pesquera del Norte Grande.
Pero hay algo en que todos los nortinos debemos centrar el interés es de urgencia que miremos hacia Arica y hagamos una ligazón estrecha con todo lo que ella representa para Chile en estos momentos.

Los ideales de la minoría que vive en esa zona no pueden sernos indiferentes. La unidad del Norte debe cobrar vigencia para que Arica no solamente piense en su pasado esplendor de puerto libre, sino que viva una realidad presente en lo económico. Creemos que las declaraciones del escritor don Benjamín Subercaseaux no tienen la gravedad que algunos quieren darle.

El ha querido expresar su inquietud frente al miraje actual de Arica. Pero ha olvidado que los derechos territoriales de los pueblos no pueden cederse cuando no hay razones valederas para ello.

Si Arica fuera tierra sin expectativas y que estuviera ahogada en infecundidad, podría mirársele como a la "tierra de nadie".

No es ese el caso. El Norte mira hacia ese territorio con profunda fe y está seguro que volverá para este puerto, la hora del júbilo y de la gloria.... ${ }^{8}$

Dos aspectos destacamos de la propuesta de Subercaseaux. La primera se refiere a de dónde emana su inquietud. De una mirada alojada en el epicentro de la frontera, lugar privilegiado para el ejercicio de la soberanía: "Interrogado de cuándo y dónde incubó estas ideas, nos respondió que estuvo quince días en Arica y al ver la situación actual pensó que esta sería la solución a muchos problemas de ese puerto". Es decir, la solución de Arica pasa por la transgresión a la soberanía, esbozando la idea de una soberanía trinacional.

No olvidemos que desde la crítica a las relaciones internacionales modernas, en las situaciones conflictivas, como es el caso de los litigios internacionales que enfrentan a dos Estados, la presencia soberana es un recurso fundamental que, no obstante, redunda en el juego de suma cero ya mencionado. En efecto: "los modernos discursos de la política ( ) cuando se encuentran en circunstancias ambiguas e indeterminadas están dispuestos a recurrir al ideal de una presencia soberana, ya sea que se trate de un actor individual, un grupo, una clase o una comunidad política" (Ashley: 2009:78). Por tanto, el planteamiento 
de Subercaseux resulta, además de polémico, heterodoxo y adelantado a su época. ${ }^{9}$

Por otro lado, su propuesta apela a un pluralismo diplomático que cuestiona los dogmas de la política exterior tradicional: el principio de integridad territorial a partir del fideicomiso, considerando que su propuesta no sería bien recibida.

Por su parte, en Bolivia, la propuesta de Ricardo Anaya ${ }^{10}$ generó más silencio de opiniones en favor o en contra, si bien no se refiere específicamente al litigio del Lauca, su planteamiento lo incluye y resuelve. Inspirado por las perspectivas de integración continental, pues considera que es posible una solución donde todos (Perú, Bolivia y Chile, además del cono sur de América) puedan ganar y compartir soberanías.

En su "Arica Trinacional" (1987), notoriamente se ubica dentro de los "practicistas". José Rodríguez Elizondo nos habla de una dicotomía: la de los practicistas, que querían una cesión de exterritorios peruanos (Tacna y Arica), y los recuperacionistas, que exigían el retorno al litoral perdido (2014:115). Los practicistas bolivianos los eran respecto de la solución del tema marítimo que lo asociaban al problema del desarrollo y lo vinculaban con el ideal latinoamericano, por tanto, también eran idealistas e integracionistas. Otro caso fue el del empresario Joaquín Aguirre Lavayén, quien construyó Puerto Aguirre buscando una salida al Atlántico e impulsó el acercamiento comercial con Chile. Fue autor de varias obras literarias, entre otras, Guano Maldito y La Patria Grande, muy pertinentes a lo señalado sobre su practicismo idealista ${ }^{11}$.

Lo interesante de Anaya, quien fue rector de la Universidad Mayor de San Simón y canciller de su país, entre otros cargos y distinciones, fue su perspectiva próxima a las teorías del desarrollo territorial, posiblemente bajo la influencia intelectual de los especialistas de la CEPAL (Devés 2003), porque considera que:

Paz y Desarrollo se niegan en aislamiento conflictivo, pero pueden armonizarse en Área de Integración, donde Bolivia y Perú dejando atrás sus resentimientos justificados pero infecundos y Chile arrogancias innobles, conjuguen esfuerzos para brindar a la región disputada y hoy atrasada del Pacífico, progreso, bienestar que a su vez contribuyan al mejoramiento integral de las naciones pactantes. Los pueblos no tienen la responsabilidad de un desgraciado pretérito y sus nuevas generaciones merecen presente y futuro prósperos (1987:138).

Entonces Anaya sugiere un acuerdo tripartito para la creación de un Polo o Área, de Paz, Integración y Desarrollo con soberanía compartida. En 1962 Anaya diseña esta propuesta, la que fue conocida por la OEA, por medio de su Secretario General Dr. José Mora y por el BID, por su Presidente, el Dr. Felipe Herrera, chileno, donde le responde a Anaya, el 25 de febrero de 1964: "Opino tal como usted, que solo dentro de un ámbito regional latinoamericano es como podemos buscar de fondo, especialmente si esta se orienta hacia perspectivas ciertas de desarrollo económico complementario" (Anaya 1987: 191). La respuesta de Herrera es consistente con su visión de América (1985).

La propuesta de Anaya fue con el tiempo desestimada tanto por pragmática como por idealista, especialmente en Bolivia, donde las visiones reivindicacionistas y emotivistas comenzaron a predominar en el discurso político y diplomático (Francisco 2009, Orias 1997, Andaluz 2000).

\section{Conclusiones}

El derrotero de la "cuestión del río Lauca" expuesto, nos muestra la presencia de diferentes actores y escalas de análisis y sus consecuencias en el desarrollo del conflicto que concluyó con la ruptura de relaciones diplomáticas entre Bolivia y Chile. Destacamos dentro de ellas la presencia de distintas racionalidades y subjetividades que determinaron, en algunos casos, ciertas consecuencias no deseadas, y en otros, varios aspectos sui generis.

En la escala regional y local-transfronteriza, vemos cómo este conflicto impactó en algunos proyectos regionales de integración física, que solicitaban la venia de las autoridades ubicadas en las respectivas capitales. Destacamos además la necesidad de las regiones de terminar con la denominada por ellos "vehemencia chauvinista" que interrumpe el desarrollo fronterizo de estas regiones periféricas. A su vez, desde la idea de pluralismo diplomático, se aprecia la tensión entre las lógicas de la diplomacia estatal y las paradiplomacias regionales.

En la escala nacional bilateral destacamos ciertas variables domésticas, como es el caso de presiones partidarias entre gobierno y oposición, 
acusando este último de "uso político de la cuestión del Lauca" al primero; por otro lado, destacamos la emergencia de la cuestión andina como una preocupación de académicos y autoridades regionales derivada del litgio.

En la escala continental e internacional, destacamos cómo el conflicto del Lauca escala hasta situarse e inmiscuirse con la agenda continental marcada por las sanciones a Cuba y el imperialismo norteamericano, conjugándose con problemas domésticos de los dos países involucrados, en lo que hoy podría llamarse emergencia de variables intermésticas.

Dos perspectivas con sentido de realidad. Los casos del jurista boliviano Alberto Salinas Baldivieso y del científico chileno Hans Niemeyer.

En lo referido a las propuestas de solución fuera de agenda diplomática, destacamos el caso de Benjamín Subercaseux y su pionera propuesta de soberanía compartida, cuestión que pone en entredicho un pilar de las relaciones internacionales modernas y que solo se comienza a problematizar en la disciplina tres décadas después. También es posible destacar a las figuras bolivianas que, desde el practicismo, se aproximaron con perspectivas heterodoxas dentro el marco general del reinvindicacionismo boliviano a soluciones novedosas, basadas en las teorías económicas, en el comercio y en la integración latinoamericana, como fueron los casos de Ricardo Anaya y Joaquín Aguirre Lavayén.

Finalmente, el estudio de este episodio de la compleja historia de las relaciones chilenobolivianas nos brinda la posibilidad de reflexionar acerca del aprendizaje que implica para ambos países la pérdida de control de un conflicto que parece menor y la desconsideración de la dimensión local en la construcción de una solución o en el establecimiento de un diálogo bilateral. Dimensión local que debería incluir a los actores subnacionales, pero sobre todo a los subregionales que habitan la frontera.

En efecto, el desafío que le plantea la dimensión local al enfoque central en materia de política exterior es, precisamente, ver en lo aparentemente pequeño, lo mayor. $\mathrm{O}$, con mayor precisión, la política exterior hacia Bolivia debe tomar en cuenta las repercusiones al desarrollo transfronterizo, que involucra al norte de Chile y al centro oeste de Bolivia, que acarrea el escalamiento de litigios jurídico-diplomáticos emprendidos desde las respectivas capitales. Aunque estamos conscientes que dicho ejercicio supone discutir pilares de las relaciones internacionales y la política exterior, como es el caso del interés nacional traducido en soberanía e integridad territorial.

\section{Referencias Citadas}

Anaya, Ricardo

1987 Arica Trinacional. Bolivia, Chile y Perú. Editorial Los Amigos del Libro, La Paz.

Araníbar, Antonio

2002 "Bolivia, Chile y Perú: Hacia un Futuro Compartido". Si Somos Americanos, vol. III, año 2.

Araníbar, Antonio

1999 "Bolivia, Chile y Perú: Hacia un Futuro Compartido". La Paz, Bolivia : Plural editores.

Andaluz, Horacio

2002 Bases jurídicas para la reintegración marítima de Bolivia: la regla pacta sunt servanda como punto cero, en Editorial UPSA, Universidad Privada de Santa Cruz de la Sierra, Bolivia.

Ashley, Richard

2009 "Desenredar el estado soberano: una doble lectura de la problemática de la anarquía", en Arturo Santa Cruz (editor), El constructivismo y las relaciones internacionales, CIDE, México, 2009, 74-98.

Bernhardson, Wayne

1985 "El desarrollo de recursos hidrológicos en el altiplano ariqueño y su impacto sobre la economía ganadera de la zona", en Chungara, Revista de Antropología Chilena, $\mathrm{N}^{\circ} 15,169-181$.

Boisier, Sergio

1987 "Notas en torno al desarrollo de regiones fronterizas en América Latina", en Estudios internacionales $\mathrm{N}^{\circ} 78$, Universidad de Chile, abril-junio, 158-191.

Castro, Luis

2004 "Recursos hídricos altoandinos, estrategias de desarrollo económico y proyectos de riego: Tarapacá 1880-1930”, en Chungara, Revista de Antropología Chilena, Vol. 36, No 1 , 205-220.

Castro, Luis

2003 "Espejismos en el desierto: proyectos ferroviarios e integración subregional (Tarapacá 1864-1937)", en Si Somos Americanos, Revista de Estudios Transfronterizos, Vol. V, 21-48.

Castro, M., Bahamondes, M., Jaime, M., Meneses, C. y Navarrete, C. 1991 "Cultura, tecnología y uso del agua en un pueblo andino del norte de Chile", en Revista chilena de Antropología $\mathrm{N}^{\circ} 10,45-69$.

Constantinou, Costas y Der Derian, James

2010 Sustainable diplomacies, Ed. Palgrave, Londres. 
Constantinou, Costas

2013 "Between Statecraft and Humanism: Diplomacy and Forms of Knowledge", en International Studies Review $\mathrm{N}^{\circ} 15,141-162$.

Cornago, Noé

2013 Plural Diplomacies: Normative Predicaments and Functional Imperatives, Ed. Martinus Nijhoff Publishers, Amsterdam.

Escobari Cusicanqui, Jorge

1978 Historia diplomática de Bolivia. Tomo 1, Talleres de la Imprenta del Consejo Nacional de Educación Superior, La Paz.

Devés, Eduardo

2003 Desde la CEPAL al neoliberalismo, en Editorial Biblos, Buenos Aires y DIBAM, Santiago.

Francisco, Mila

2009 "La cuestión Marítima en la política exterior de Chile y Bolivia", en Diplomacia $\mathrm{N}^{\circ} 118,47-69$.

Galdames, Luis y Ruz, Rodrigo

2010 "La Junta de Adelanto de Arica y John V. Murra. Dos lecturas sobre el desarrollo andino en el norte de Chile", en Chungara, Revista de Antropología Chilena, Volumen 42, $\mathrm{N}^{\circ} 1,257-270$.

Gómez, Luis

1998 Ferrocarriles en Bolivia del anhelo a la frustración 1860-1929, Ed. UMSA, La Paz.

González, Sergio

2006 Arica y la triple-frontera. Integración y conflicto entre Bolivia, Perú y Chile, Editorial Aríbalo, Iquique.

González, Sergio

2011 "Las históricas relaciones entre Tarapacá y Oruro: la frustrada tentativa de integración transfronteriza durante ciclo de expansión del salitre (1864-1928)", en Revista de Geografía Norte Grande, № 50, 63-85.

Gundermann, Hans y Héctor González

(2009:118) "Sociedades indígenas y conocimiento antropológico. Aymaras y Atacameños de los siglos XIX y XX", en Chungara, Revista de Antropología Chilena, Volumen 41, $\mathrm{N}^{\mathrm{o}} 1,2009,113-164$.
Harms, Carlos

1930 Los grandes problemas de la zona norte de Chile, Ed. La Ilustración, Santiago.

Herrera, Felipe

1985 Visión de América Latina, 1974-1984, editorial Pehuen, Santiago.

Larraín, Horacio

1974 "Antecedentes históricos para un estudio de la reutilización de suelos agrícolas en la Pampa del Tamarugal, Provincia de Tarapacá, Chile", en Revista Norte Grande, Vol. 1, No 1, 9-22.

Niemeyer, Hans

1985 "Nota del editor" en el artículo de Bernhardson, Wayne 1985 "El desarrollo de recursos hidrológicos en el altiplano ariqueño y su impacto sobre la economía ganadera de la zona", en Chungara, Revista de Antropología Chilena, $\mathrm{N}^{\circ} 15,169-181$, p. 169.

Orias, Ramiro

1997 "Derecho del mar y cooperación trinacional: una perspectiva boliviana", en Barrios, Raúl (editor). Bolivia, Chile y Perú. Una opción cooperativa, Editorial Plural, 71-104.

Rodríguez Elizondo, José

2014 Historia de dos demandas: Perú y Bolivia contra Chile, Editorial Aguilar, Santiago.

Sanz, Carlos

2015 "Agentes, redes y culturas. Senderos de renovación de la historia diplomática", en Actas del XII Congreso de la Asociación de Historia Contemporánea: pensar con la historia desde el siglo XXI", Ediciones de la Universidad Autónoma de Madrid, Madrid, 687-706.

Tomasek, R.D.

1967 "The Chilean-Bolivian Lauca River Dispute and the O.A.S.", en Journal of Inter-American Studies, $N^{\circ}$ 9, Vol. 3 , 351-366.

Van Kessel, Juan

1985 "La lucha por el agua de Tarapacá. La visión andina", en Chungará, Revista de Antropología Chilena $\mathrm{N}^{\circ} 14$, 141-156.
1 El diario La Tercera de Santiago del 5/10/2010 marca el retorno de este tema a la agenda diplomática boliviana 38 años después, a saber:

El conflicto del río Lauca, que en 1962 terminó con la ruptura de relaciones diplomáticas entre Chile y Bolivia, fue reflotado por el gobierno de La Paz, que pidió incorporarlo en la agenda bilateral de 13 puntos.

El punto fue puesto sobre la mesa en el encuentro del Grupo de Trabajo encargado de avanzar en la temática de recursos hídricos y el Silala, otro de los cauces que son objeto de discrepancias.

Según una nota de la Cancillería boliviana, su delegación "introdujo la problemática del río Lauca para lo cual solicitó que se instalen en dicho río, estaciones hidrométricas dentro de 120 días". La delegación chilena indicó que consideraría esta solicitud. Sin embargo -según la versión boliviana-, la representación chilena "no se mostró dispuesta a suscribir el Acta.
A diferencia del Silala, el Lauca nace en el altiplano chileno, cruza a territorio boliviano y culmina su recorrido en el lago Coipasa.

En el gobierno de Aguirre Cerda se inició un plan para regar el valle de Azapa con sus aguas, lo que tensionó las relaciones con Bolivia. En la administración de Jorge Alessandri se ordenó abrir las compuertas del río. La Paz se quejó ante la OEA y el quiebre de relaciones.

2 Discurso del canciller chileno, Carlos Martínez Sotomayor, del 27 de marzo de 1963. Citado por (Escobari Cusicanqui 1978:169)

3 El Tarapacá de Iquique, 1 de enero de 1962.

4 Ofensiva, Sucre, 23 de abril de 1962

$5 \quad$ Revista Chungara $\mathrm{N}^{\circ}$ 14, 1985, Nota del Editor, p. 169

6 Periodista, diplomático y escritor chileno. Ácido polemista e intérprete del acontecer político de su época.

$7 \quad$ La Defensa de Arica, 17/07/1962. 
$8 \quad$ La Defensa de Arica, 18/07/1962.

$9 \quad$ No olvidemos que la teoría posmoderna de las relaciones internacionales si bien encuentra evidencia que coteje sus postulados en la modernidad, sus postulados se esbozan a finales de la década de 1980 .
10 Otros autores con ideas similares pero propuestas en la década de 1990 fueron Antonio Araníbar (1999 y 2002) y Ramiro Orias (1997).

11 Fue un activo participante de los Encuentros de historiadores, intelectuales y cientistas sociales chileno-bolivianos hasta un año antes de su fallecimiento. 